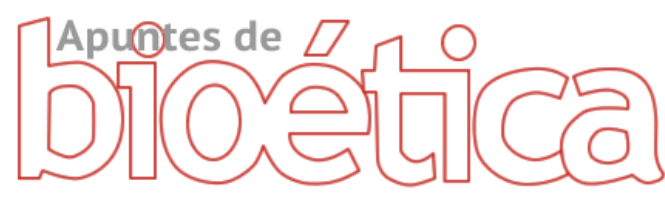

https://doi.org/10.35383/apuntes.v2i2.285

\title{
El urgente desafío de promover el valor de la vida humana
}

\author{
Alejandra Mónica Planker de Aguerre ${ }^{1}$
}

\section{INFORMACIÓN DEL ARTÍCULO RESUMEN}

\section{Historia del artículo:}

Recibido el 22 de setiembre de 2019

Aceptado el 27 de diciembre de 2019

\section{Palabras claves:}

Persona

Dignidad

Aborto

Inicio de vida

Naturaleza humana
Para promover el valor de la vida humana desde la concepción/fecundación, es necesario instalarse con firmeza en el concepto de naturaleza humana. Desde el aspecto biológico al espiritual, la naturaleza de la persona clama por la continuidad de "entidad" de los padres a los hijos.

Se tratará el concepto de persona, su origen, sus características fundantes, el criterio de dignidad y se reflexionará en la paradójica posibilidad de hacer un mal, queriendo un bien, aparentemente.

Es una síntesis apretada de las razones filosóficas por las que la vida humana naciente ha de ser protegida y tutelada.

Ha llevado tiempo reconocer el valor de la persona humana, fundada en su dignidad. Sin embargo la "atrofia" cognitiva y volitiva que sufre el hombre hace que en la actualidad sea una tarea realmente titánica la de sostener que la vida humana vale desde su inicio en la concepción/fecundación. La presencia cada vez más difundida de los debates proaborto, señalan esta realidad. Quizás volver a las fuentes de la comprensión de la naturaleza corpóreo-espiritual del hombre sea el camino de retorno.

The football of the outsiders: Notes about the new ethical conceptions related to the human development of elite athletes

\section{ABSTRACT}

\footnotetext{
1 Profesora de Filosofía por la Pontificia Universidad Católica Argentina. Magister en Ciencias de la Familia por la Universidad de Málaga. Maestranda en Bioética por la Pontificia Universidad Católica Argentina. Asesora Técnica pedagógica del Instituto para el Matrimonio y la Familia de la Pontificia Universidad Católica Argentina Email: a.planker@gmail.com. ORCID: https://orcid.org/0000-0002-8826-3627.
} 


\section{Keywords:}

Person

Dignity

Abortion

Start of life

Human nature
To promote the value of human life from conception / fertilization, it is necessary to settle firmly in the concept of human nature. From the biological to the spiritual aspect, the nature of the person cries out for the continuity of "entity" from the parents to the children.

The concept of person, its origin, its founding characteristics, the criterion of dignity will be treated and it will be reflected in the paradoxical possibility of doing evil, wanting a good, apparently.

It is a tight synthesis of the philosophical reasons why nascent human life has to be protected and protected.

It has taken time to recognize the value of the human person, founded on their dignity. However, the cognitive and volitional "atrophy" that man suffers makes today a truly titanic task to maintain that human life is worth since its inception in conception / fertilization. The increasingly widespread presence of pro-abortion debates points to this reality. Perhaps returning to the sources of understanding the corporeal-spiritual nature of man is the way back.

\section{Metodología}

"Nuestra sensibilidad es la de un ser espiritual, nuestro espíritu es el de un ser sensible; la ley más central de nuestra naturaleza, al mismo tiempo que inclina nuestro espíritu hacia la carne, levanta nuestra carne hacia el espíritu... La operación más pesadamente carnal (el hecho de comer, por ejemplo) implica un cierto consentimiento y un cierto gozo del espíritu; recíprocamente, la más noble actividad espiritual se apoya sobre un mínimun de resonancia afectiva."

Gustave Thibon, Lo que Dios ha unido. Plantín, Buenos Aires, 1952.

El hombre además de definirse como animal racional se expresa como una unidad sustancial de cuerpo y alma. El ser humano es afectado integralmente por el mundo que lo rodea y así es que responde, en las distintas circunstancias de su vida, en cuerpo y alma, en carne y espíritu, como un todo único y singular.

\section{¿Cómo se integran el espíritu y el cuerpo?}

Es común escuchar la afirmación: "El hombre tiene cuerpo y alma". Para referirnos correctamente y con justicia a la naturaleza humana hemos de afirmar que el hombre "es" cuerpo y alma. Agregamos algo más: cuando lo definimos como "animal racional" no entendemos a la racionalidad solamente como la capacidad de pensar, discurrir o argumentar, sino que es la espiritualidad del hombre desplegada a través de su inteligencia y su voluntad libre. La grandeza de todo ser humano encuentra explicación en esta capacidad de trascendencia, en esta necesidad de salir a encontrar la verdad y el bien que una nostalgia originaria nos la muestra como un derecho connatural de cada persona. En el hombre se percibe "una abundancia capaz de entrar en contacto con la intimidad de los restantes seres humanos y también con lo más hondo y significativo con lo más real- del universo material que lo circunda, hasta sus dimensiones más ínfimas; y susceptible de elevarse, en el otro extremo, hasta el propio Ser de Dios".

El alma humana espiritual nada podría "ejecutar" sin su unidad con el cuerpo, a través del cual se expresa y manifiesta en el mundo. Amamos el bien en cada cosa buena que se nos presenta. Conocemos la verdad en cada ser que nos habla a partir de su misma 
existencia. Gozamos del abrazo de la persona que amamos, pero sabemos que ese abrazo significa algo si en verdad testimonia el abrazo atemporal que sólo pueden darse dos almas que aman.

Nuestro cuerpo permite el contacto, el enlace y la comunicación con el mundo material, pues siendo también material puede captar sensiblemente las características de nuestro alrededor.

El conocimiento humano se inicia en los sentidos para perfeccionarse y completarse en el entendimiento. Los órganos de los sentidos son los que captan las cualidades sensibles de las cosas (color, olor, sabor, sonido, texturas, temperaturas), que están en las cosas mismas. A partir de este primer modo de conocimiento comienza el proceso cognoscitivo que conduce al conocimiento de las esencias, tarea específica de la inteligencia, que "penetra" en la intimidad de la realidad, viendo lo que las cosas "son" verdaderamente. $^{2}$

Nuestra relación con el mundo no es sólo a través del conocimiento sensible e intelectual, sino también a partir de las tendencias apetitivas, que nos inducen a aceptar o rechazar aquello que hemos percibido como bueno o malo, conveniente o perjudicial, beneficioso $o$ nocivo. Los movimientos realizados por estos apetitos o tendencias son las pasiones, que según su modo de respuesta frente a los objetos de deseo o rechazo serán emociones o sentimientos ${ }^{3}$.

\footnotetext{
${ }^{2}$ Tomás A., De Veritate q.2, art.3. arg.19 "Praeterea, nihil est in intellectu quod non sit prius in sensu." (Nada hay en la inteligencia que no haya estado primero en los sentidos). Ya Aristóteles en De Anima había sostenido la misma noción al afirmar que la inteligencia es una "tabula rasa" que necesita adquirir el conocimiento del mundo circundante.

${ }^{3}$ Leemos en Rodríguez L. A., Ética, EUNSA, Pamplona, España, 1984, pág.1234: "Las pasiones son actos o movimientos de las tendencias sensibles que tienen por objeto un bien captado por los sentidos. (...) Como todo acto apetitivo, las pasiones proceden siempre de un conocimiento previo. Igual que el querer racional es precedido por el conocimiento intelectual, las pasiones se desencadenan a partir del conocimiento sensible, ya sea de la sensibilidad externa (vista, oído, etc) o de la interna (imaginación, memoria): ante la vista de un alimento, puede surgir un deseo sensible de comerlo; ante un recuerdo desagradable, la tristeza".
}

Del mismo modo que el conocimiento, estas tendencias apetitivas o "apetitos" son del orden de la sensibilidad y también de la espiritualidad. El apetito espiritual o volitivo es la voluntad, con su atributo esencial, la libertad.

La inteligencia se inicia en su conocimiento a partir de los datos que le aportan los sentidos. La voluntad se inclina hacia los bienes que son primero apetecidos o deseados por las potencias de la sensibilidad corpórea.

Reiteramos entonces que los actos de estas potencias de la sensibilidad corpórea son las pasiones. Son sensibles porque se manifiestan en el cuerpo y a través de éste: palidecer, aceleración del ritmo cardíaco, enrojecer, temblores, etc. (Amor, odio, tristeza, gozo, audacia, temor, esperanza, desánimo, ira). Las pasiones son el modo en que el hombre, frente a una realidad que lo afecta, la valora y consecuentemente la acepta o rechaza

\section{Es común escuchar sobre el valor de la dignidad humana, pero ¿En qué consiste la dignidad de la persona humana?}

El hombre no es sólo un individuo más entre el resto de los individuos vivientes. Hemos descubierto que su naturaleza corpóreo-espiritual, que le permite trascender el tiempo y el espacio, lo convierte en un ser único e irrepetible: es persona y de allí su dignidad en la jerarquía de los seres:

"La dignidad del hombre, (...) se corresponde con la presencia en él de un alma espiritual e inmortal, necesaria, que recibe en sí misma $-y$ no en la materia- el acto personal de ser. Espiritualidad, necesidad e inmortalidad 
son, pues, los títulos metafísicos por los que la persona humana (...) goza de una particular eminencia ontológica, de una excelsa dignidad entitativa".

La dignidad se muestra. Pero la imposibilidad de demostración, racional o experimental, no impide ni merma la riqueza intrínseca y natural de cada hombre, varón o mujer. El valor de la persona es evidente, axiomático e irrefutable.

\section{¿A qué nos referimos con el concepto "persona"?}

Buscando en los orígenes de las palabras encontramos que los griegos utilizaban el término "prósopon" para significar "persona", y que también le daban el mismo nombre a las máscaras que utilizaban los actores en las obras de teatro que representaban ante el pueblo. A través de estas máscaras los personajes se expresaban sobre la arena de un anfiteatro, manifestando las alegrías, dolores, picardías y verdades que el autor proponía para cada uno de ellos, configurando distintas personas.

Por su parte, los latinos derivaron la palabra persona del verbo "personare" -sonar a través de-, $y$, manteniendo semejanza con la raíz griega también nos indican que la persona es aquella a través de la cual suena una voz. Suena la voz del actor, y mediante ella, la voz del autor de la pieza teatral. En una visión cristiana, es la voz misma del Creador del hombre que quiere y encuentra un modo de revelarse en el ser de su creatura.

Podemos, entonces, asistidos por la tradición de la cultura, afirmar que la persona no es sólo un individuo que se distingue corporal o materialmente de los otros individuos de la misma especie, sino que llamamos persona a la naturaleza humana,

\section{individual y especial a través de la cual Dios se revela en la Creación.}

A través de la existencia de cada ser humano, Dios habla y comunica Su amor. ¿Cómo puede entenderse esta afirmación de una manera más concreta? Pongamos un ejemplo: Un escritor escribe su libro porque desea la existencia de aquello que concibe como bueno y por esa razón lo llama a la existencia. Lo mismo sucede con el hombre. En cada acto de Creación Dios afirma su decisión de que lo que es bueno, exista. Así con cada uno de nosotros, aunque si bien se puede comprender, a veces resulte difícil vivirlo...

Hay quienes consideran que para ser persona es necesario que ésta manifieste con evidencia y claridad sus capacidades intelectuales y volitivas y que lo haga de manera perfecta. Sabemos, que dada la imperfección y corruptibilidad de la materia no siempre es posible que así sea. La enfermedad, las discapacidades naturales o adquiridas y el mismo paso de los años no siempre posibilitan esta expresión, incluso las capacidades aún no desplegadas de un niño en gestación, son considerados por algunos como elementos claros para negar esta realidad. Recordemos que el operar sigue al ser, pero el ser no se agota en el operar. ¿Qué significa? Que cada ser, el hombre en este caso, obrará de acuerdo a sus capacidades específicas. Si estas no son posibles de ser biológicamente manifestadas, no merma de ninguna manera el carácter de dignidad del ser personal.

El ser persona no se define porque seamos más inteligentes o menos, más hermosos y armoniosos físicamente, más voluntariosos y emprendedores en las tareas cotidianas, sino que nos determinamos como personas por haber sido llamados como únicos e irrepetibles a la existencia, por Alguien que vio que nuestra existencia era 
buena y siendo consecuente con Su amor, queriendo que lo bueno exista, nos dio la vida. Si alguno no acepta la decisión generosa de un Creador en ponernos en el mundo viviente, al menos considerará que las leyes del cosmos, superando todo azar, concluyeron, bastante armoniosamente, en nuestra existencia.

Por esta razón, la persona es digna. La dignidad de la persona responde al valor intrínseco de la misma y de este modo se hace patente en la misma existencia personal.

No puedo argumentar por qué es valiosa mi existencia, no puedo demostrarle a los otros las razones últimas de mi existir. Esta imposibilidad de demostración se funda en la dignidad de ser persona.

La dignidad de la persona es un principio ${ }^{4}$ evidente de la naturaleza humana. Al ser principio puede mostrarse su verdad, pero no se puede demostrar. Para ejemplificar digamos que se daría la misma situación de indemostrabilidad si quisiera demostrar el color rojo de una flor roja ante la presencia de esa flor roja. Frente a ella muestro su rojez, pues es evidente, patente que así lo es, no es necesario demostrarlo ${ }^{5}$. Es cierto que no todos podrán, quizás, percibir la misma intensidad de color. Pero no cabe duda que la rosa es y con su color, y eso se muestra, con evidencia, obviamente.

¿Cómo se relaciona esta evidencia en el inicio de nuestra vida? Cada uno es persona, a través de quien "suena la voz de un autor". Así es que hablamos de "procreación". En el instante mismo de nuestra gestación, una palabra divina, articulada a través de la voz de

${ }^{4}$ Otros primeros principios son por ejemplo: "El ser es y el no ser (la nada) no es" o "Todo lo que está compuesto por materia se corrompe" o "Todo ser que actúa lo que hace en razón de un fin que es su bien". Todos son de evidencia inmediata. Si necesitaran ser demostrados, ya no serían principios ni primeros

${ }^{5}$ La demostración se realiza mediante una argumentación o razonamiento llegando a una conclusión que se deduce de razones previamente expuestas. los padres fue pronunciada como un sí, para dar inicio a la vida. Los padres, en una entrega de amor mutuo y completo, permiten que un nuevo ser humano exista, incluso sin conciencia de su presencia actual.

$Y$ aquí surge la "nostalgia de infinitud, eternidad y perfección". Esta palabra divina que nos llama a la vida es también la misma que aspiramos a escuchar en cada una de nuestras búsquedas de verdad, bien o belleza. Es una búsqueda constante y universal. Es la razón por la cual no estamos satisfechos e intuimos a la inmortalidad como algo que "merecemos".

Estas búsquedas de sentido se dan a través de nuestras acciones en la sociedad, en la familia, en el estudio, en el trabajo, en cada día de nuestra vida. Así desplegamos el sentido de nuestra existencia ante nosotros y ante los demás.

El amor se entiende como entrega y como inicio y fin (o meta) de la existencia humana. Se inicia la vida en la entrega y en la recepción del amor, se sostiene la vida en el amor y se aspira a dejar una huella que señale a otros el surco en el amar.

Y la capacidad de amar y de ser amados, el permitirnos entregar amor y ser receptores del amor, nos dignifica y nos permite la valoración y apreciación de lo que somos en cuanto somos, ni más ni menos. Únicos e ineludiblemente incomparables.

Tomar conciencia de esta realidad de ser personas, desde el momento de la concepción hasta la muerte, tendría que generar en cada ser humano una profunda convicción (y decisión) de que la vida humana ha de ser protegida siempre, independientemente de los modos que encuentre para expresarse. Sucede que, frente a embarazos inesperados, la razón y los afectos se nublan, se pierde conciencia del valor de la vida y se la relativiza 
según el estupor, el miedo, la vergüenza o el sufrimiento por no encontrar salidas. Que los protagonistas de un embarazo inesperado, madre y padre principalmente, pero también familia o amigos circundantes, puedan pensar críticamente sobre la vida que se inicia, es fundamental para dar respuesta aún en las situaciones más adversas.

\section{Situación actual de la naturaleza humana: debilidad y fragmentación}

Con mayor asiduidad vemos dibujarse una tremenda crisis en la intimidad de la naturaleza humana.

Esta crisis de identidad se espeja en la situación vital del hombre actual: inquietud y temor por el futuro $\mathrm{o}$ indiferencia $\mathrm{y}$ resignación frente a lo que podría acontecerle. Actitudes contradictorias, pero usuales

Como todo tiempo de crisis $^{6}$, es un tiempo especialmente adecuado para revisar y discernir qué está sucediendo y qué rumbo tomar para sobrellevar y superar las dificultades y también para aprovechar las oportunidades de crecimiento que habrá que aprender a distinguir.

El Padre José Kentenich, en una serie de conferencias que se publicaron bajo el título "Que surja el hombre nuevo" hace referencia a esta situación señalando que la crisis del hombre se expresa en una atrofia $y$ fragmentación de la naturaleza humana.

\section{Atrofia como debilidad (a causa de una pobre "alimentación")}

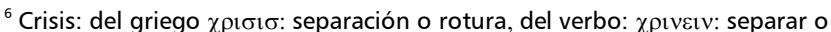
decidir. De aquí la palabra crítica, que significa separar o distinguir para ver de qué se trata algo. Se relaciona con discernimiento sobre algo, intentando, por ejemplo, diferenciar lo superficial de lo importante, lo accidental de lo sustancial.
Al referirse a la atrofia, el $P$. Kentenich explica que esta significa que en el hombre, en modo general y abarcador, "se ha agotado fuertemente su caudal espiritual". Esto conlleva a que al hombre actual le resulte difícil comprender y vivir en la vida cotidiana la relación necesaria que existe entre el orden natural y el orden sobrenatural. Recurriendo a la etimología de las palabras es interesante ver que el término atrofia significa sin nutrición. La falta de nutrientes materiales genera debilidad corporal. La falta de nutrientes espirituales provoca debilitamiento, apatía, insensibilidad.

El P. Kentenich escribe, en primer lugar, que la atrofia espiritual limita y reduce la capacidad de acceder a la mirada de lo sobrenatural. El hombre se limita a resolver las dificultades de la vida sólo desde el plano natural y se empobrece su existencia:

"Porque se ha eliminado toda la realidad sobrenatural, el hombre de hoy debe asumir las dificultades de la vida sólo desde el plano natural. Y no logra asumirlas. No encuentra el sentido de los acontecimientos de su vida. El hombre gira en torno de su propio polo, no tiene parámetros, no tiene puntos de referencia para comprender cabalmente su vida. Porque los parámetros y puntos de referencia los obtenemos cuando meditamos sobre la vida sobrenatural".

Si la actitud del hombre es autorreferencial, si no sale a mirar qué hay más allá de sí mismo, no encontrará parámetros en los que apoyarse u orientarse para comprender integralmente su vida. La cuestión es cómo asumir los problemas corrientes de la vida diaria, no en el plano teórico, sino concretamente ${ }^{7}$. Perder la mirada

\footnotetext{
${ }^{7}$ Viktor Frankl al tratar el tema del sentido del trabajo dice: "Hemos dicho que no basta con preguntar por el sentido de la vida sino que hay que responder a él respondiendo ante la vida misma. De donde se desprende que esta respuesta ha de darse, en cada caso, no con palabras, sino con hechos, con la conducta. La respuesta que se dé debe responder, además,
} 
de lo sobrenatural es perder la confianza en la divina Providencia y en el sentido que tiene la existencia, aunque a veces este se oculte $u$ oscurezca según la limitada capacidad de visión humana.

Pareciera que el hombre se abocara a alcanzar cada día un nuevo objetivo, en competencia consigo mismo. Si lo alcanza, es exitoso, si no lo alcanza, es probable que sucumba a la depresión causada por una errónea decepción de sí mismo. Se podría pensar que esta es la razón por la cual, aún para los niños más pequeños, los días, los meses e incluso cada año de vida transcurren con tanta rapidez. Tanta es la ansiedad que no hay tiempo para detenerse. Es una rueda vertiginosa, que no da lugar al aburrimiento, pero sí a la indiferencia y a la minusvaloración de cada momento como único que es.

¿Y cuál es la relación con el inicio de la vida? Frente a la urgencia de alcanzar éxito ${ }^{8}$ en la vida, la llegada de un nuevo ser que convoque a detener el paso, para descentrarse de uno mismo y así pensar en el otro con una mirada y acción oblativas, resulta molesto, escandaloso, perturbador y debe eliminarse el obstáculo.

En una disposición tal sólo queda lugar para el temor al futuro, o para la indiferencia o para la provocación de acciones temerarias (deportes extremos, "jugar" al límite, etc). Esperar lo inesperado es gran parte de la fortaleza del ser humano que se sabe finito pero con dimensiones más valiosas de infinitud y trascendencia. Tal como lo planteaba Heráclito de Efeso: "Si no se espera, no se encontrará lo inesperado; puesto que lo inesperado es difícil y arduo".

a todo lo que hay de concreto en la situación y en la persona, asumir dentro de sí, en cierto modo esta concreción." Viktor F., Psicoanálisis y existencialismo, Fondo de Cultura Económica, México, 2005, 2a ed, $11^{\text {a }}$ reimpr., pág. 170

${ }^{8}$ Éxito: Es interesante la etimología del término: del verbo latino "exire", salir, que derivó luego en salir, ir fuera, pero triunfante, lo contrario de fracasar.
Cuando las energías para avanzar en el camino de la existencia dependen sólo de una iniciativa humana, pero nada más que humana, es esperable que la atrofia espiritual decline en atrofia existencial a la que se podría llamar muerte o agonía de la persona por inanición a causa de la carencia de verdad y sentido como nutrientes y sostén.

Leemos en un artículo del Dr. Alfonso López Quintás: “... si el sentido de la vida desaparece o se difumina, surge el hastío, el tedium vitae o desgana de vivir".

Sigue el texto "Sorprende ver -indica Henri J. M. Nouwen- que gran parte de nuestra vida la pasamos sin reflexionar sobre su sentido. No es de extrañar que haya mucha gente tan ocupada $y$, al mismo tiempo, tan hastiada".

En general, para "ocultar" el hastío se recurre a la hiperactividad, al constante ajetreo para evitar la mirada sobre lo que está sucediendo en el interior.

Una vida de este tipo es una vida "adulterada." Ya no es una vida que manifiesta el gozo de saberse digna, sino que busca convertirse en otra cosa pretendiendo hallar algo que la haga "sentir de verdad". La persona que busca satisfacción sexual fuera del matrimonio es adúltera y así, analógicamente, la existencia personal que busca fuera de sí misma el sostén, sentido y finalidad de su vocación más profunda realiza un camino semejante.

Otra consecuencia de la atrofia espiritual: la incapacidad para tomar decisiones. El hombre actual encuentra dificultad en decidir por sí mismo, necesita del aval de los demás. En la soledad no encuentra sosiego, la entiende como aislamiento y esto le genera inseguridad personal. Esta reflexión sigue la línea de pensamiento del Dr. Viktor Frankl, quien escribe acerca del "vacío 
existencial" como un fenómeno extendido en el siglo XX (también XXI). Hace referencia a dos razones por las que se desencadena este vacío existencial:

“...puede deberse a la doble pérdida que el hombre tiene que soportar desde que se convirtió en un verdadero ser humano. Al principio de la historia de la humanidad, el hombre perdió algunos de los instintos animales básicos que conforman la conducta del animal y le confieren seguridad; seguridad, que como el paraíso le está hoy vedada para siempre: el hombre tiene que elegir; pero además, en los últimos tiempos de su transcurrir, el hombre ha sufrido otra pérdida: las tradiciones que habían servido de contrafuerte a su conducta se están diluyendo a pasos agigantados. Carece, pues, de un instinto que le diga lo que ha de hacer y ya no tiene tradiciones que le indiquen lo que debe hacer; en ocasiones no sabe siquiera lo que le gustaría hacer. En su lugar, desea hacer lo que otras personas hacen (conformismo) o hace lo que otras personas quieren que haga (totalitarismo)".

Se puede inferir que la caída en la masificación es una derivación casi obligada de esta pérdida de rumbo que sufre la sociedad de nuestro tiempo.

Se puede inferir que la caída en la masificación es una derivación casi obligada de esta pérdida de rumbo que sufre la sociedad de nuestro tiempo.

Se puede inferir que la caída en la masificación es una derivación casi obligada de esta pérdida de rumbo que sufre la sociedad de nuestro tiempo

Entonces, además de la incapacidad de relacionar el plano natural con el sobrenatural y de la dificultad para tomar decisiones por sí mismo, el P. Kentenich sostiene que la tercera atrofia ocupa terreno en el corazón del hombre.

La atrofia del corazón se manifiesta en la pérdida de capacidad de pensar con claridad. Inteligencia, voluntad y afectividad no se integran. Se desborda la afectividad por no tener la regulación de la inteligencia y de la voluntad, o se la inhibe o reprime, fragmentando las capacidades humanas y por ende, a la persona misma. Surge un hombre que no puede, no quiere, no desea o simplemente no sabe amar (por no tener verdadera experiencia). Este hombre no experimenta amor ni tampoco reconocimiento de sí mismo ni de los demás.

\section{El aborto como respuesta frente a la atrofia y negación del valor de la vida naciente}

No es casual que frente a la atrofia del corazón, que impide dirimir con justicia sobre el sentido de la vida, se yerga la posibilidad de acabar con todo lo que molesta. Y que esta eliminación se exprese como un derecho del más fuerte sobre el más débil. Así surge en nuestra sociedad, que labra la libertad de los hombres sobre la tierra de los "derechos humanos", el "derecho al aborto". Se levantan las banderas del derecho a la interrupción legal, médica, voluntaria o quirúrgica del embarazo, -y quien sabe cuántos eufemismos más se inventarán- , para no nombrar directamente lo que es la eliminación de una vida humana indefensa e inocente.

Como hemos estado tratando sobre la natural condición inteligente y libre de todo ser humano, me interesa considerar por qué la inteligencia y la voluntad libre, en su búsqueda de verdad y bien, pueden no reconocer a la vida naciente en la plenitud de su dignidad. En palabras más sencillas, por 
qué puede pensarse en el aborto como un derecho o al menos como un acto que puede realizarse voluntariamente como un bien para quien lo considere así.

Cabría dentro de esta paradoja otra inquietud más: si realmente es un acto personalísmo de la voluntad, y queda dentro de la esfera de lo esperable como modo de obrar humano, ipor qué debería establecerse una ley que lo legalice? Es absurdo pensar que es necesario legalizar lo que pretende ser un bien. Al menos que la pretensión sea falsa, falaz y perversa.

Entonces hablemos de aborto voluntario. Es decir, de finalización voluntaria del embarazo. Cabe una pregunta más todavía: si es voluntario, si la persona embarazada, como bien se usa decir actualmente, decide terminar con su embarazo. ¿Es necesario legislar sobre esa voluntad? ¿Es necesario legitimar esa acción? ¿Por qué? Todos tenemos conciencia de que el hombre cuando obra lo hace por un fin bajo razón de bien. La voluntad no obra sino para conseguir un bien. Siempre. Si es un bien lo que la voluntad libremente procura (incluso en relación al aborto se arguye que quienes quieren hacerlo porque así lo desean son discriminadas injustamente y victimizadas y consideradas negativamente por la sociedad que no les permite alcanzar su bien, dada su situación de vulnerabilidad, indefensión, o lo que sea que las lleve a tomar tal decisión ...), entonces si es un bien... ¿Es necesario debatir, reflexionar, considerar, argumentar, mostrar, relatar, sobre la legalización del aborto, si es lo que mejor puede acontecer como decisión libre y voluntaria para una persona que lo razona y lo ve como tal?

Me permito pensar que hay algo que no está bien enfocado. Es que legislar sobre si es posible matar o dejar vivir a un inocente, más cuando se encuentra al cuidado de la única persona que puede hacerse cargo de su vida hasta el momento de su nacimiento, es realmente un absurdo. $\mathrm{Y}$ no podemos olvidar que esa madre, o si se la prefiere llamar progenitora, es lo que es por su relación con el hijo, embrión o feto. Aunque la mujer gestante no quiera reconocer al fruto de la concepción como un hijo, no es otro ser que un hijo. Y ella, la madre, es madre, aunque no lo esperara o deseara. Interrumpir el embarazo, finalizarlo, es consecuencia de una ignorancia que impide que la voluntad libre elija el bien. No conocer que el ser humano es capaz de encontrar salidas a las posibles situaciones de dolor, sufrimiento, soledad, violencia, incomprensión, es el camino más directo al error en el pensar y en el obrar.

\section{¿Podemos considerar al aborto como un acto voluntario?}

Lo voluntario es fruto de una elección. Para elegir, primero habrá que conocer las posibles opciones. ¿Se les ofrecen verdaderas opciones a las mujeres embarazadas que están en situación de vulnerabilidad, desamparo, violencia, pobreza, indefensión? El aborto es la elección por el fracaso: de la familia que no contiene, que no sabe cómo hacerlo. Fracaso de la sociedad que condena a los más débiles, que elimina la fuerza del futuro, y es fracaso del Estado que es ineficiente en políticas públicas de educación $\mathrm{y}$ de salud.

Se habla del aborto como una ampliación de los derechos humanos, dentro de los Derechos Sexuales y Reproductivos. Se lo asienta sobre valores muy nobles: libertad de elección, derecho a la salud, promoción de autonomía...

El derecho a la libertad de elección de cómo gestionar sobre el propio cuerpo o en torno a si tener o no hijos, cuándo, cómo, con quien...no está mal. Son derechos y deben ser protegidos. ¿Pero a costa de la muerte de un 
otro? Con contundencia científica se ha hablado de un código genético diferente, no es una parte de la madre la que se desarrolla, es otro individuo, claro que de la misma especie pero distinto, absolutamente. Planificar la familia desde la eliminación del hijo ya concebido no es un derecho para nadie. Reclamar el aborto es proponer lo que ninguna ley, nacional ni internacional, podría establecer: el derecho de la mujer a matar a sus hijos no nacidos. Y un hijo no es tal sólo si el deseo de la madre lo determina, como se ha escuchado decir en estos tiempos. Es como si creyera que yo soy quien soy solo porque alguien, (no Alguien) me desea en la existencia. Seguimos existiendo, íntegra e ineludiblemente, aunque no nos pensemos unos a otros. Y si la objeción es: no lo piensa como hijo, no lo quiere como hijo, por lo que no le da tal entidad, lo esencial, lo que lo hacer ser, es que ya es, existe, vive como ser humano, independientemente de su deseo. No tendrá aun desarrolladas todas su capacidades, nosotros tampoco. Pero no nos habilita a provocar la muerte de nadie.

La mujer que llega al aborto es una víctima más de un sistema social perverso que dice que mujer autónoma es la que toma sus propias decisiones imponiendo su interés individual sin tomar en cuenta el daño que pueda infligir a otro. $Y$ en la soledad toma la decisión. Y más sola queda luego. Porque es cierto: la decisión fue absolutamente personal, pero no tan libre como se la presentaron. Para poder elegir, debemos primero conocer: cuanto mejor conocemos, mejor elegimos y más libres somos. Algunas preguntas: ¿Qué lugar ocupó, para quien no quiere continuar con el embarazo, el consentimiento informado? ¿Se le dijo lo que debía saber? Se le ofrece objetivamente el conocimiento de la vulnerabilidad a la que queda expuesta una mujer luego de un aborto iSe le ofrece otra posibilidad, como la adopción, a quien no puede hacerse cargo de la maternidad?

\section{Recomendaciones}

> Sin educación y sin conocimiento no hay capacidad humana para elegir. Sin elecciones personales no se ejerce la libertad. Sin libertad somos esclavos, indefectiblemente, de las decisiones de otros. Frente a la posibilidad de la legalización del aborto, en la que se juega la vida de un nuevo ser humano, reitero indefenso e inocente, estamos obligados a ofrecer soluciones: acceder a una prevención primaria (antes del embarazo), mediante una educación realmente integral. Promover espacios de contención, acompañamiento, revisar, reactivar la ley de adopción. Son importantes los cuidados puerperales, pero reales y efectivos. Si somos creativos, lo logramos. Medios humanos y económicos, en más o en menos, siempre hay. Faltan decisiones firmes. $Y$ abnegación.

$>$ Y no nos olvidemos de otros importantes protagonistas del inicio de la vida, que también deberán hacerse cargo, o se les deberá permitir hacerse cargo: también existen los varones. Ellos también son capaces de preservar la vida. Y el peso que se comparte, hace el camino más liviano, siempre.

$>$ Todos tenemos derecho a la vida, todos, los nacidos y los por nacer, siempre, porque toda vida vale por igual. Pero no perdamos tiempo.

No sigamos desgastando energías en buenos propósitos. O lo que sería peor en ver quien gana una batalla ideológica, para ver quien permite que prevalezca el más fuerte. Pongamos manos a la obra. Nuestros hijos lo 
merecen. Toda vida vale y vale todo nuestro esfuerzo.

\section{Bibliografía}

Heráclito D. É.( 500 aC), Filósofo griego, circa.

Ibíd. Pág. 54

Ibíd. Pág. 55.

Melendo G. T. (2001). Las dimensiones de la persona, Madrid: Palabra.

López Q. A. (2008). El ideal de la unidad y el sentido de la vida, recuperado el 11, noviembre de http://cofalcala.weebly.com/uploads/3/7/2 /1/3721901/launidadysentidodelavida.pdf

Nouwen, H. (1995). Aquí y ahora. Viviendo en el Espíritu, Madrid: San Pablo.
P Kentenich J. (1983) Que surja el hombre nuevo, Santiago de Chile: Editorial Schoenstatt.

P Kentenich J.op.cit Pág. 57

P.Kentenich J. op.cit. Pág.58

Rodriguez L. A. (1984). Ética, EUNSA, Pamplona, España.

Tomás A, De Veritate q.2, art.3. arg.19 "Praeterea, nihil est in intellectu quod non sit prius in sensu."

Viktor F. (2005), Psicoanálisis y existencialismo, México: Fondo de Cultura Económica.

Viktor F. (1981), El hombre en busca de sentido, Barcelona: Herder 